\title{
CRIAÇÃo e APLiCABILIDAde de ReCURSOS TECNOLÓGICOS NO ENSINO DE BIOLOGIA
}

\author{
CREATION AND APPLICABILITY OF TECHNOLOGICAL RESOURCES IN \\ TEACHING BIOLOGY
}

DOI: $\underline{\text { 10.23926/RPD.2526-2149.2020.v5.n3.p1964-1979.id910 }}$

\section{Jones Baroni Ferreira de Menezes \\ Doutorando em Educação (UECE) \\ Professor na Faculdade de \\ Educação de \\ Crateús/Universidade \\ Estadual do Ceará \\ (FAEC/UECE) \\ jones.baroni@uece.br}

\section{Edilane Ribeiro do Nascimento Graduando em Ciências Biológicas (UECE) edilane.nascimento@aluno.u ece.br}

\section{Marcos Paulo Lopes Rodrigues}

Graduando em Ciências

Biológicas (UECE)

marcos.paulo@aluno.uece.br

\section{Ana Carolina Oliveira Silva \\ Graduando em Ciências \\ Biológicas (UECE) \\ ana.carolina@aluno.uece.br}

Resumo: O uso de tecnologias está sendo amplamente difundido no ensino, com objetivo de dinamizar o processo de ensinoaprendizagem, sobretudo neste período pandêmico, no qual aconselha-se o distanciamento social, paralisando as atividades presenciais das escolas, tornando o ensino mediado pelas tecnologias da informação e comunicação. Nesse propósito, este artigo pretende apresentar a produção de materiais didáticos digitais que possam ser utilizados nas diversas áreas do ensino de Ciências e Biologia. $\mathrm{O}$ projeto desenvolveu materiais como cartilhas, livros digitais, mapas conceituais, cruzadinhas, caça-palavras, jogos educacionais, arquivos de aúdios e vídeos, utilizando ferramentas como Canvas, Kahoot, CmapTools, Spreaker, Flipsnack, Geniol, Educolorir, Youtube e o Google Site. Assim, consideramos importante a produção de materiais educativos utilizando recursos tecnológicos, de modo a propiciar a diversificação e dinamismo nas aulas, além de desenvolver habilidades tanto nos docentes como nos discentes.

Palavras-chave: Tecnologias Educacionais. Docência. Aprendizagem.

Abstract: The use of technologies is being widespread in teaching, with the objective of streamlining the teaching-learning process, especially in this pandemic period, in which social distance is advised, paralyzing the classroom activities of schools, making teaching mediated by information technologies. information and communication. In this regard, this article aims to present the production of digital teaching materials that can be used in the various areas of science and biology teaching. The project developed materials such as booklets, digital books, concept maps, crosswords, word searches, educational games, audio files and videos, using tools such as Canvas, Kahoot, CmapTools, Spreaker, Flipsnack, Geniol, Educolorir, Youtube and Google Site. Thus, we consider it important to produce educational materials using technological resources, in order to provide diversification and dynamism in classes, in addition to developing skills in both teachers and students.

Keywords: Educational Technologies. Teaching. Learning. 


\section{INTRODUÇÃO}

As primeiras décadas do século XXI, devido à difusão do uso da internet, possibilitando um processo de globalização, uma facilidade de acesso, produção e circulação de informação, além de minimizar o distanciamento físico das pessoas, fez emergir uma nova conjuntura social, denominada de "Era digital" (SANTOS; CATARINO, 2016). Nesse contexto social, o aluno não deixa de aprender ao sair da escola, principalmente quando este tem acesso à internet, onde consegue ter informações do assunto que lhe convém, na hora que lhe interessa e na intensidade que deseja. Isso tem tornado a produção do conhecimento mais "fácil, imediato, onipresente e acessível" (GÓMEZ, 2015, p.14).

Ademais, Quintanilha (2017) reconhece que o profissional docente tem um grande desafio quando se trata de ensinar os alunos desta geração. Moran (2001) já afirmava que o uso das tecnologias no contexto educacional poderia gerar uma revolução na forma dos alunos e professores verem o processo de ensino e aprendizagem, o que pode, segundo Tezani (2011), desenvolver competências e habilidades de comunicabilidade, agilidades, busca de informações e autonomia individual. Deste modo, o uso de recursos tecnológicos avança constantemente permitindo uma aproximação com os discentes, proporcionando um processo de troca de conhecimentos, agregando conhecimento no processo de fazer pedagógico, podendo tornar o ensino mais dinâmico, interativo e facilitador da aprendizagem (MACHADO; LIMA, 2017).

Obviamente o professor, ainda que recém-formado, necessita utilizar as tecnologias ao seu favor, para isso, o conhecimento se faz necessário, para que os benefícios tecnológicos sejam notados no processo de ensino-aprendizagem, caso contrário, a tecnologia pode se tornar vilã da aprendizagem (MEDEIROS; QUEIROZ, 2018). Somado a todos os benefícios do uso das tecnologias da educação, precisa-se acrescentar ainda que, a educação acompanha a evolução da sociedade, desta forma o mercado de trabalho se torna competitivo e exigente, demandando profissionais em constante formação, assim sendo, os cursos de licenciatura já devem adicionar em seus currículos orientações para os professores em formação, bem como a própria utilização das TIC pelos docentes que encontram-se vinculados a estes cursos, já que eles tornam-se espelhos de atuação dos futuros docentes (DE MENEZES; MOURA; DE ARAUJO SOUSA, 2019).

Devido à pandemia do novo coronavírus (COVID-19) que assola o mundo em 2020, as atividades educacionais por meio das tecnologias da informação e comunicação tornaram-se inevitáveis, sobretudo pela necessidade do distanciamento social como principal medida governamental para conter a disseminação viral e minimizar os casos e óbitos pela doença 
(OMS, 2020). Assim, evidenciou-se a necessidade do uso das tecnologias no processo de ensino e aprendizagem, propiciando que os professores se reinventassem para utilizar ferramentas síncronas e assíncronas que contribuíssem em suas aulas.

Nesse ínterim é que o projeto de pesquisa de Tecnologias Educacionais (EPTEDUC), vinculado a uma universidade estadual no Nordeste brasileiro, ganha força em meio a um cenário que exige a tecnologia atrelada à educação. $\mathrm{O}$ projeto atua de modo a auxiliar os professores que desejam ideias de atividades práticas e tecnológicas que possam ser utilizadas em sala de aula. Além de ideias de atividades, o projeto também busca sistematizar um material de informações, que podem ser utilizados por alunos de quaisquer idades para complementar seu aprendizado, centrando a formação da cultura digital (NUNES et al., 2014).

O processo de sistematização perpassa pela definição de um local onde serão armazenados estes materiais produzidos (objetos de aprendizagem - OA), a este denominado de Repositório de Objeto de Aprendizagem. Ele é um espaço virtual que facilita a busca e localização desses OA (RODRIGUES; BEZ; KONRATH, 2014).

Visto ao exposto, o trabalho objetiva apresentar os materiais produzidos pelos alunos bolsistas e voluntários do EPTEDUC, depositados no ROA, fazendo uma análise da criação e potencialidades de aplicação dos recursos tecnológicos utilizados. Contudo, inicialmente trataremos do contexto da inclusão das tecnologias no contexto educacional, sobretudo, por meio da produção de materiais didáticos tecnológicos.

\section{TECNOLOGIa E EdUCAÇão: PRODUÇão de MATERIAL DidÁtico digITAL}

No cenário tecnológico em que a sociedade está inserida, o uso de recursos tecnológicos avança constantemente e os professores precisam acompanhar esse processo, nesse contexto o desenvolvimento de materiais didáticos contribui para uma formação continuada dos docentes, que precisam de novas competências para atender as necessidades impostas pela educação (DE CARVALHO; DE CARVALHO, 2017). Machado e Lima (2017) consideram que o uso de tecnologias por parte dos docentes permite uma aproximação com os discentes, proporcionando um processo de troca de conhecimentos, onde ambos agregam conhecimento no processo de fazer pedagógico.

Do mesmo modo, os alunos que fazem o uso de ferramenta tecnológica no desenvolvimento dos próprios materiais para estudarem despertam habilidades como autonomia e senso colaborativo, contribuindo para sua aprendizagem (SOUZA FILHO; SOUZA-ALBA; GIBIN, 2017). Assim, estende-se essa efetividade de formação também para 
os bolsistas de iniciação cientifica, vinculados à cursos de licenciatura, e estagiários de docência, a criação e utilização deste tipo de material na realidade das escolas em que estes estão inseridos, compreendendo que os alunos possuem níveis diferentes de relação com às tecnologias, o que faz desenvolver materiais que atendam a todos (HERRERO, 2019).

Para contribuir em todo este contexto, a criação e disponibilização de materiais didáticos digitais é fundamentalmente importante para contribuir no planejamento didático das aulas. A estes materias denomina-se objetos de aprendizagem (OA). Segundo Aguiar e Flôres (2014), não há um consenso quanto a conceituação do $\mathrm{OA}$, mas que sua definição deve levar em consideração a utilidade, importância e tipo de abordagem proposta. Sumariamente, Tarouco, Fabre e Tamusiunas (2003) designam um Objeto de Aprendizagem como um material produzido para apoiar o processo de ensino e aprendizagem.

Para Abdelbasset et al. (2015), os OA apresentam quatro características fundamentais: a reusabilidade (capacidade de ser reutilizado em diversas situações e formas), acessibilidade (disponível online na internet e seja possível de operar em diferentes plataformas), granularidade (tamanho coerente e compatível enquanto conteúdo educacional) e agregação (pode ser reutilizado como ele é ou pode também ser agregado na construção ou adaptação de outro objeto de aprendizagem).

A partir da criação dos OA, viu-se a necessidade de uni-los em um mesmo local, sendo este virtual e de fácil acesso a toda a comunidade educacional. Assim, para garantir a acessibilidade e reusabilidade dos OA, é fundamental que estes sejam armazenados em um ambiente que permita sua pronta localização e recuperação. Para tal, os repositórios digitais têm sido utilizados para esse fim, e são chamados de Repositórios de Objetos de Aprendizagem (ROA) (RUSSELL et al., 2013).

Os ROA devem ter como principais características: a historicidade, que é a capacidade de manter diferentes versões e registros do seu catálogo, e não ser volátil, ficando os dados preservados e não modificados durante as atualizações do repositório, além de um filtro de relevância, preservando apenas dados relevantes e úteis para a futura utilização destes. Ademais, também pode ser pontuado as possiblidades de compartilhamento e colaboração com os demais ROA (ABDELBASSET et al., 2015).

Os sites se fazem a opção mais viável para a construção desses repositórios digitais, pois, para Quintanilha (2017), não exigem grandes investimentos financeiros, fazendo com que todos possam fazer uso deste método. Além disso, outra vantagem, é a variedade de conteúdo que pode ser disponibilizado, que "[...] vão desde compartilhamento de informações, textos e 
vídeos, até a criação de jogos, questionários, pesquisas e avaliações” (QUINTANILHA, 2017 p. 253).

Com a acessibilidade que a internet nos oferece, o ROA, tornou-se parte essencial do projeto, para aliar o virtual ao real.

\begin{abstract}
A internet, as plataformas digitais e as redes sociais, merecem uma consideração especial como instâncias de comunicação e intercâmbio que favorecem a interação e a participação dos interlocutores como receptores e transmissores de intercâmbios virtuais humanos (GÓMEZ, 2015 p. 21).
\end{abstract}

Com a oportunidade de troca de material por meio da interação na plataforma, outras sugestões de tecnologias são evidenciadas, como a criação de um canal no YouTube, que se torna extremamente útil para compartilhamento direto de informações e, se trabalhado de uma forma de entretenimento conteudista, fará o processo de aprendizagem mais interessante, instigante e fácil (QUINTANILHA, 2017).

Para mais, de forma a compreender como ocorreu o processo de criação dos objetos de aprendizagem e do repositório destes, a seguir é apresentado o percurso metodológico desta investigação.

\title{
3 Metodologia
}

A pesquisa caracteriza-se como um estudo de caso descritivo, de abordagem qualitativa que, segundo Minayo (2001, p.21), objetiva "aprofundar-se no mundo dos significados das ações e relações humanas, um lado não perceptível e não captável em equações, médias e estatísticas".

Ela está vinculada ao grupo de estudos e pesquisa em tecnologias educacionais (EPTEDUC), desenvolvido na unidade de uma universidade estadual situada nos Sertões de Crateús, no estado de Ceará, Brasil e que objetiva o estudo sobre a abordagem das tecnologias no processo de ensino e aprendizagem, bem como desenvolver recursos didáticos digitais para que professores em atuação e em formação possam utilizá-los em salas de aula.

Tais recursos são desenvolvidos por integrantes do grupo, bem como os demais alunos nas diversas disciplinas do curso de licenciatura em Ciências Biológicas, que com o consentem com a disponibilização do material para o repositório virtual do projeto, através do sítio https://sites.google.com/uece.br/epteduc/in\%C3\%ADcio, permitindo o acesso e colaboração de outras pessoas aos materiais produzidos. Neste mesmo local, há a disponibilização das produções cientificas do grupo. Assim, o detalhamento dos materiais produzidos é detalhado na seção a seguir. 


\section{Resultados}

Os materiais produzidos atenderam, inicialmente, a necessidade dos professores e bolsistas participantes (Tabela 1). Essas produções e o uso de materiais autorais, desenvolvidos para uma finalidade específica, estimulam tanto a criatividade dos discentes, como dos docentes que participam do processo de desenvolvimento do material, despertando, muitas vezes, habilidades como autonomia e senso colaborativo, contribuindo para a aprendizagem de todos (OLIVEIRA MONTE et al., 2016). Ademais, também pode contribuir para uma formação continuada dos docentes, que precisam de novas competências para atender as necessidades impostas pela educação (CARVALHO; CARVALHO, 2017).

Quadro 1 - Listagem das ferramentas tecnológicas utilizadas na criação dos materiais didáticos produzidos pelo integrantes do grupo de pesquisa

\begin{tabular}{|l|l|l|}
\hline \multicolumn{1}{|c|}{ Materiais produzidos } & \multicolumn{1}{c|}{$\begin{array}{c}\text { Ferramenta tecnológica } \\
\text { utilizada }\end{array}$} & \multicolumn{1}{c|}{ Link de acesso } \\
\hline Cartilhas & Canvas & $\underline{\text { https://cutt.ly/ffaDD7K }}$ \\
\hline E-books & Flipsnack & $\underline{\text { https://cutt.ly/XfaDLce }}$ \\
\hline Mapas Conceituais & CmapTools & $\underline{\text { https://cutt.ly/mfaDXZT }}$ \\
\hline Cruzadinhas & Educolorir & $\underline{\text { https://cutt.ly/7faDBK9 }}$ \\
\hline Caça-palavras & Geniol & $\underline{\text { https://cutt.ly/zfaD0Lk }}$ \\
\hline Jogos educacionais & Kahoot! & $\underline{\text { https://cutt.ly/afaD92A }}$ \\
\hline Podcast & Spreaker & $\underline{\text { https://cutt.ly/OfaD8le }}$ \\
\hline Vídeos & iMovie e Youtube & $\underline{\text { https://cutt.ly/nfaD4Y0 }}$ \\
\hline
\end{tabular}

Fonte: Elaborada pelos autores.

Inicialmente, foram desenvolvidas cartilhas sobre Direitos Humanos (Educação em Direitos Humanos, diversidade e valorização multicultural; Direito da Criança, Adolescente e Idoso) como ilustra a figura 1, e Astronomia (movimento da Terra), contando com a participação de alunos do curso de Pedagogia que estavam inseridos na disciplina de Ensino de Ciências.

As cartilhas são bastante utilizadas como recurso facilitador de aprendizagem em várias áreas de ensino na sala de aula e auxiliam no processo de estruturação de saberes por parte dos alunos que obtém contato com essa ferramenta, devendo levar em consideração sobre a relevância e atualidade das informações constantes, bem como a atratividade visual que a mesma pode conter, favorecendo uma melhor compreensão do assunto abordado (GALINDONETO et al., 2017; RAMOS; ARAÚJO, 2018). 


\section{FIGURA 1-}

Figura 2 - Modelo de cartilha sobre os direitos humanos, produzidas pela ferramenta Canva

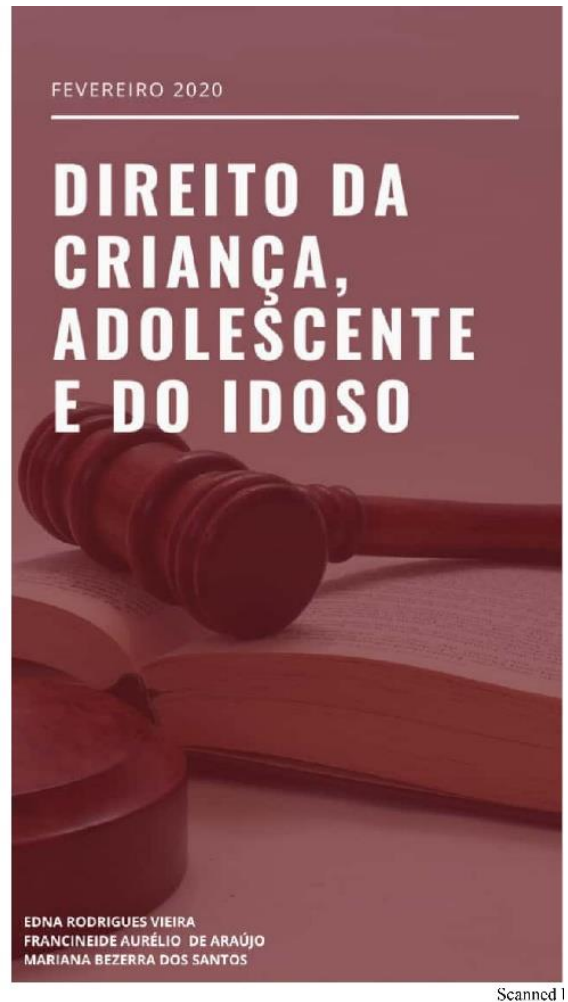

Fonte: Acervo do EPTEDUC.

Também foram elaborados mapas conceituais. Para Grillo e Lima (2003, p. 1), “os Mapas conceituais (MC) são representações gráficas de conjuntos de conceitos organizados sob a forma de diagramas, que indicam relação entre esses conceitos". Para além, os autores salientam que os MC não possuem uma formatação preestabelecida, dependendo da perspectiva do(s) indivíduos que os produzem.

Os MC foram produzidos por alunos do curso Técnico em Química Integrado ao Ensino Médio enquanto participavam de um processo de estágio supervisionado na disciplina de Biologia, os mapas versaram sobre Recursos Naturais (Recursos Naturais e Recursos Nãorenováveis) e Poluição (figura 2) acerca de poluição de modo geral e contaminação. Percebeuse que muitos alunos encaram esses mapas como um excelente método de revisão do conteúdo, uma vez que é necessário um estudo sobre a temática para inserir as palavras-chaves que formam cada mapa conceitual, facilitando a assimilação dos conteúdos.

Figura 3 - 
Figura 4 - Mapa conceitual sobre contaminação, produzidas por alunos do ensino médio, como parte integrante da aula do estágio em docência

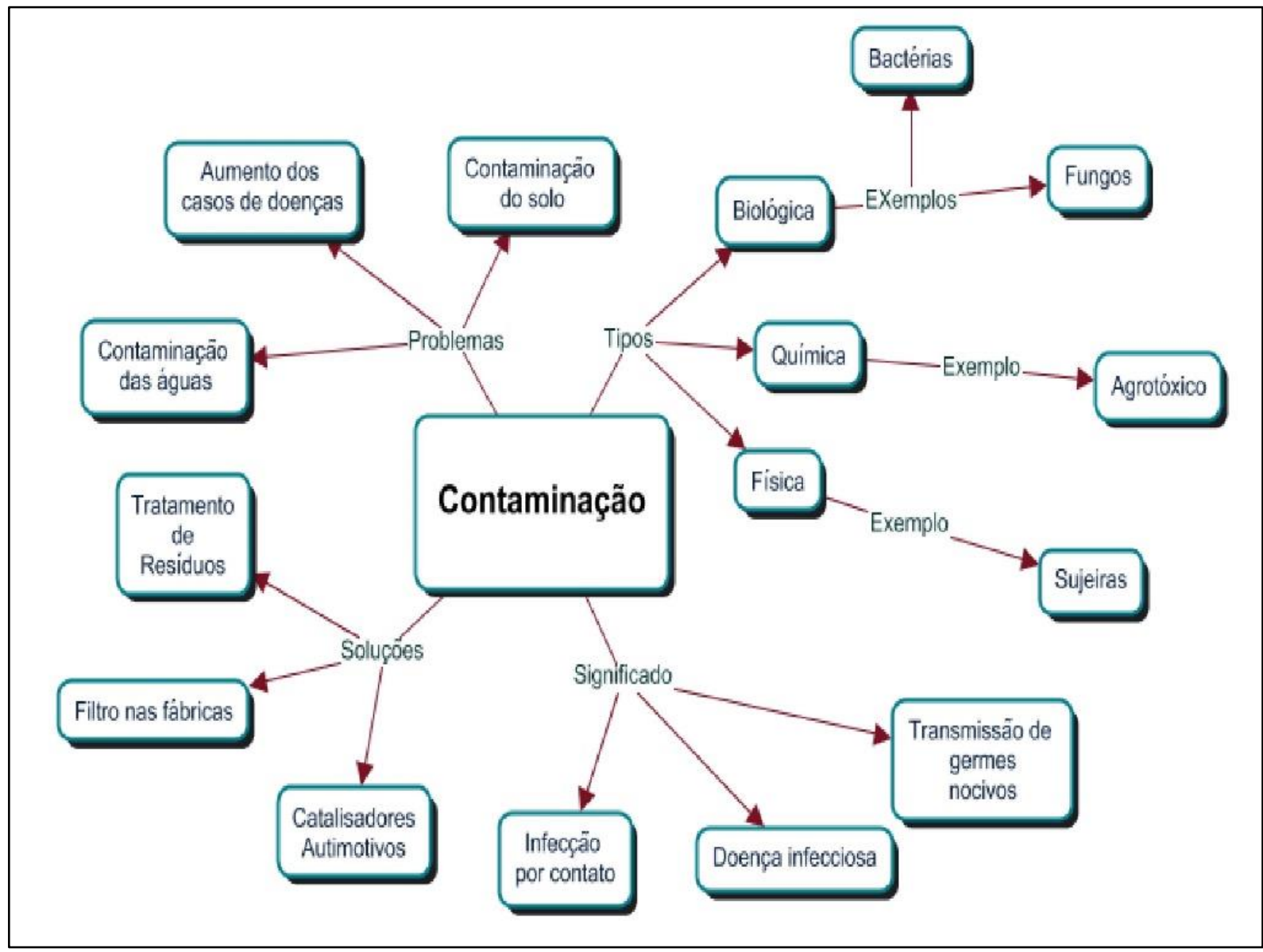

Fonte: Acervo do EPTEDUC.

A utilização dos mapas conceituais deve-se aos estudos de John Novak, contribuindo no entendimento do estudante sobre determinado conteúdo, de forma a gerar ao aluno a oportunidade de aprender a aprender, estando, portanto, sedimentado na Teoria de Aprendizagem Verbal Significativa de Ausubel (MACHADO et al, 2019).

Contudo, o uso de mapa conceitual apresenta vantagens e desvantagens. Entre as possíveis vantagens, destaca-se: enfatizar a estrutura conceitual da temática abordada; mostrar que os conceitos, algumas vezes, podem se inter-relacionar, proporcionando uma visão integrada do assunto. Em relação as desvantagens, cita-se a ausência de um corpo autoexplicativo, posto que é preciso que o criador elucide acerca dos termos utilizados para estruturar o mapa; além de autor dispor de um domínio significativo sobre o conteúdo abordado no mapa para possibilitar um melhor entendimento nos ligamentos das palavras com os conceitos (SILVA; LOREZENTTI, 2018)

Conforme informado anteriormente, alguns materiais também foram produzidos pelos próprios professores ou estagiários para a aplicação durante a prática docente. Para este 
momento, pontuamos o desenvolvimento das cruzadinhas (palavra cruzada) e caça-palavras como auxílio didático durante as aulas.

A presença destes recursos didáticos não é muito utilizada em determinada áreas, entretanto na Educação são recursos frequente para o professor, sobretudo na educação infantil e nas series iniciais do ensino fundamental. Contudo, aqui, as mesmas foram utilizadas produzidas para serem aplicadas no ensino médio.

As cruzadinhas apresentam temáticas sobre Anatomia, precisamente acerca do Sistema Nervoso (figura 3) e Ecologia (Relações Ecológicas), enquanto o caça-palavras abordou sobre Biomas Brasileiros (Figura 4).

Em conformidade com Martin et al. (2018), as cruzadinhas são métodos eficazes para substituição de avaliações escritas padrões, uma vez que é possível aplicar mais questões nas cruzadinhas, sendo que nessas questões o tema é cobrado de modo mais objetivo. Similarmente, as palavras cruzadas, para Reis e Vieira Júnior (2019), aponta como importante para o desenvolvimento motor a partir do uso de caça palavras, ao levar em consideração que o aluno deverá marcar as palavras, bem como o desenvolvimento de habilidades linguísticas (FERREIRA; SANTOS, 2017), já que o discente precisará encontrar palavras em meio a letras soltas, além da possibilidade de interdisciplinaridade, quando aplicado em disciplinas distintas das de linguagens. 
Figura 5 - Palavra cruzada sobre anatomia e fisiologia do Sistema Nervoso, criada por meio do aplicativo Educolorir

\section{Tecido Nervoso}

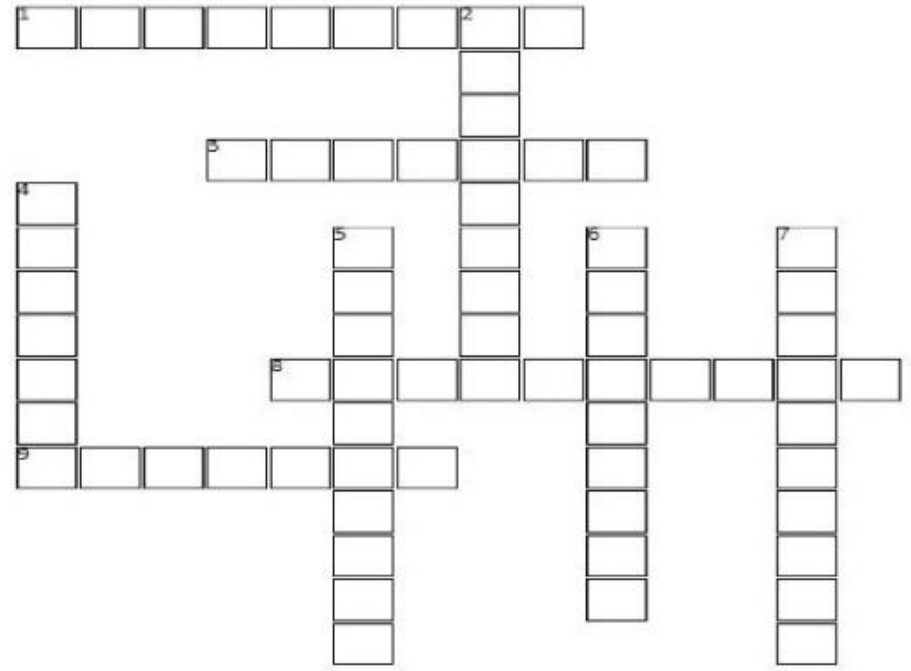

Horizontais

1 O tecido Nervoso age juntarente crmo tecido para capacitar a percepcão de varaç̄̃es co meio

O encéfalo e a médula espinnal săo partes do Sistema Nervoso

8 Os neurứnics__transjotam os impulsos dos receptores ao SNC

9 F a transmissăo do impulsc nerusc entre dois nervos ou entre o nervo e um ćrgäo efetor. como o muscue

\section{Verticais}

Os__ềm a capacidade ce procizir potenciais de açäo su impulsos.

4 Os neurónios Transportem os impuisos do SNC ès células efetoras

3 O equilírio do corpo, também é chamado de

As

As sus:enta, nutre e protege os

Nervos, Gărgl os a teminaç̋̈es nervosas sâo partes do Sisterta Nevoso

1. Eoiteliai 2. Neurồnios 3. Central 4. Motores 5. Homeostase 6. Neurogia 7. Periférico 8. Sensoriais 9 . Sinapse

Fonte: Acervo do EPTEDUC. 
Figura 6 - Caça-palavras sobre os biomas brasileiros, produzido pelo aplicativo Geniol

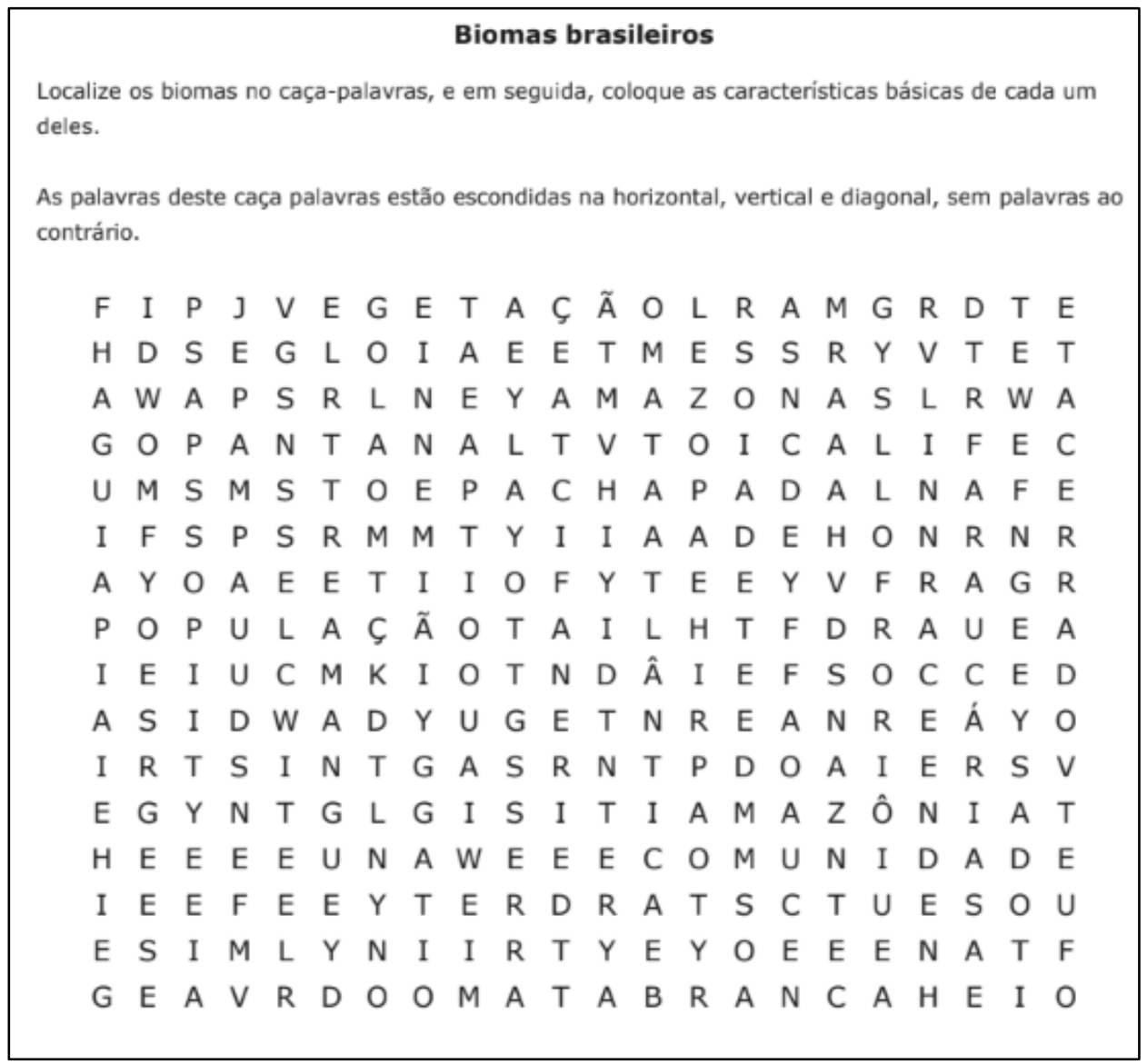

Fonte: Acervo do EPTEDUC.

Essas atividades lúdicas ganham espaço no contexto educacional, de modo a contribuírem no desenvolvimento intelectual e social do educando, além de estimular a participação nas atividades, independentemente do nível e da idade dos participantes, gerando a possibilidade de formas significativas para a aprendizagem (OLIVEIRA ALKIMIN, 2014).

Além dos materiais já detalhados, foi confecciona um e-book sobre Astronomia e um jogo em Geociências (Placas Tectônicas), em consonância com o abordado na BNCC, singularmente nos campos de experiência do Ensino Fundamental para área de conhecimento Terra e Universo (BRASIL, 2017). 
Figura 7 - Capa do livro digital sobre Astronomia e Sistema Solar

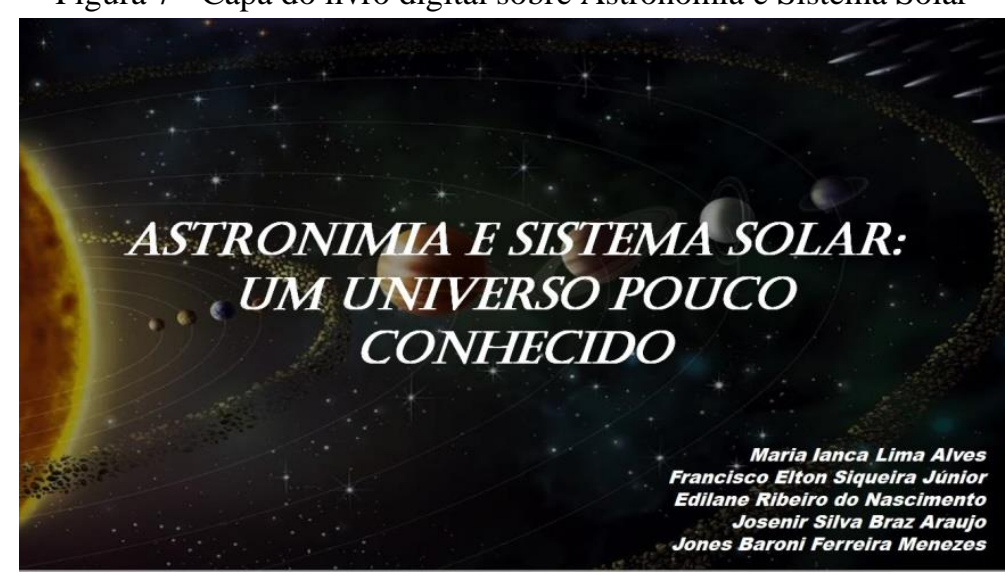

Fonte: Acervo do EPTEDUC.

$\mathrm{O}$ uso de e-book favorece o processo de ensino-aprendizagem pelo dinamismo e versatilidade possível de se obter com a aplicação do recurso, uma vez que pode apresentar imagens, hiperlink de vídeos, jogos, entre outros recursos, além de levar em consideração a preocupação ambiental, não utilizando papel no processo (THEISEN; PAVÃO, 2019).

Já sobre a escolha da referida temática está pautada na, ainda, ineficiência dos cursos de formação de professores em abordarem esta temática, mesmo estando pautando nas normativas curriculares brasileiras, sendo este, portanto, um material facilitador do entendimento dos principais conceitos, bem como ser suporte para planejamento das aulas. Em consonância ao exposto, Langui e Nardi (2009) realçam que os conceitos básicos de astronomia não fazem parte dos cursos de formação inicial de professores, levando muitos docentes a desconsiderar conteúdos deste tema em seu trabalho docente ou apresentam dificuldades ao ensinar os conceitos basilares de fenômenos relacionados à astronomia

Além disso, uma outra possibilidade de recurso didático são os podcasts, que “ferramenta de produção midiática em áudio, distribuído digitalmente (geralmente em arquivo de áudio mp3 ou via streaming) e ouvido sob demanda (on demand), ou seja, o ouvinte que escolhe o que ouvir, quando, onde e por meio de qualquer dispositivo" (CORADINI; BORGES; DUTRA, 2020), podendo ser abordado uma diversidade de conteúdos. Contudo, é importante haver uma definição de tempo e linguagem, para que se adaptem ao público alvo.

Tal ferramenta apresenta relevância no ensino para discentes e docentes, uma vez que a temática trabalha pode ser acessada com facilidade, tanto para gravar como escutar as aulas fora do ambiente escolar, fator preponderante a ser considerado nos dias atuais onde muitas vezes não há tempo para parar e estudar em um local fixo (MAFORT; RAMOS; FERNANDESSANTOS, 2019). 
Assim, atendendo a necessidade da abordagem de temas da atualidade, foram desenvolvidos um podcast sobre o Dietilenoglicol, substância tóxica encontradas na fabricação de cervejas Belorizontina, em Minas Gerais, para esse podcast foi entrevistado um Professor Doutor em Química e Pós-graduado em Farmacologia.

O podcast está disponível no Spreak, foi produzido por gravador de áudio de celular e com duração de 04:39 minutos, foram feitos questionamentos como: qual a substância encontrada na cerveja, como ela pode contamina-la e os perigos biológicos para as pessoas que ingerem. Com isso, o conteúdo pode ser aplicado tanto em aulas de química, como bioquímica, por se tratar de um conteúdo químico, mas com aplicações em organismo vivos.

E durante a pandemia do COVID-19, foi criado o canal do EPTEDUC na plataforma de vídeos Youtube, onde estão armazenados vídeos educativos e lives produzidos pelo grupo. Destacamos a abordagem sobre a temática da ansiedade na quarentena, a partir da perspectiva de um professor universitário, na qual tem formação acadêmica em psicologia e pedagogia, com doutorado em educação. Esse vídeo encontra disponível na plataforma de vídeos YouTube do projeto, bem como no Repositório Online de Atividades (ROA) e aborda uma introdução acerca do tema, assim como ações e atitudes que podem ser feitas como métodos alternativos para minimizar ou solucionar os momentos ansiosos.

O acesso de informação pela plataforma do YouTube, causa interesse por parte dos estudantes, visto que é um site muito utilizados pelos mesmo para visualizarem tanto vídeos aleatórios como de conteúdo educativo, como por exemplo vídeo aula. Em concordância com Silva, Pereira e Arroio (2017), os estudantes assistem aos vídeos naturalmente, sendo um hábito já agregado na rotina dessa geração moderna tecnologicamente. $\mathrm{O}$ autor ainda complementa que esse método ainda pode ser ampliado em outras áreas, logo ocorre uma abordagem mais ampla de temáticas por meio do YouTube.

Face ao exposto, a ideia da produção do ROA/EPTEDUC e outros canais de comunicação é disponibilizar esses materiais didáticos para utilização no processo de ensinoaprendizagem, contribuindo com alunos e professores, para uma educação mais contextualizada, interdisciplinar e de uma prática docente que possa diversificar as estratégias e recursos didáticos, além de aproximá-los das tecnologias e sua associação no contexto educacional. 


\section{CONSIDERAÇões FinAIS}

Considera-se a importância na produção de materiais utilizando recursos tecnológicos para uma diversificação e dinamismo nas aulas, facilitando o processo de ensino-aprendizagem e desenvolvendo habilidades tanto nos docentes como nos discentes. Além disso, é salutar ressaltar que a criação de materiais tecnológicos não se destina apenas aos professores e sim também aos alunos, dando a eles mais autonomia de pesquisa e desenvolvimento.

No entanto, a produção implica em algumas dificuldades, como o pouco domínio das ferramentas tecnológicas e de conteúdos, que são relevantes com o estudo para compreensão, o que engrandece o saber de quem está produzindo, auxilio não só na formação inicial dos discentes, mas na formação continuada dos docentes.

Com isso, considera-se que o uso das tecnologias no ensino vem trazendo diversos benefícios e que eles não ficam restritos apenas a um lado do processo de ensino, mas é estendido de forma ampla para atender as necessidades tanto de alunos como de estudantes.

\section{REFERÊNCIAS}

ABDELBASSET, Rouabah; SELMANI, Larbi; AKHROUF, Samir; YAHIA, Belayadi. Dihya: An intelligent learning object repository. In: 2015 International Conference on Interactive Mobile Communication Technologies and Learning (IMCL). IEEE, 2015. p. 154-159.

AGUIAR, Eliana Vigerion Barreto; FLÔRES, Maria Lucia Pozzzati. Repositórios de Objetos de aprendizagem. In: Tarouco et al. (Org.) Objetos de aprendizagem: teoria e prática. Porto Alegre: Evangraf, 2014.

BRASIL. MEC/CONSED/UNDIME. Base Nacional Comum Curricular (BNCC). Educação é a Base. Brasília, 2017

CARVALHO, Nerivaldo Braz; CARVALHO, Anna Christina Farias. Uso dos Recursos Tecnológicos Atuais e sua contribuição no processo de Ensino-Aprendizagem na Escola Municipal Érico Veríssimo, Simões-PI. ID on line REVISTA DE PSICOLOGIA, v. 10, n. 33, p. 112-125, 2017.

FERREIRA, Dennys Gomes; SANTOS, Juraci Pessoa. Jogos de construção interdisciplinar nos anos iniciais. Revista Eletrônica Mutações, v. 8, n.14, p. 182-184, 2017.

CORADINI, Neirimar Humberto Kochhan; BORGES, Aurélio Ferreira; DUTRA, Charles Emerick Medeiros. Tecnologia educacional podcast na educação profissional e tecnológica. Revista eletrônica científica ensino interdisciplinar, v. 6, n. 16, p. 216-230, 2020 .

GALINDO NETO, Nelson Miguel et al. Primeiros socorros na escola: construção e validação de cartilha educativa para professores. Acta Paulista de Enfermagem, v. 30, n. 1, p. 87-93, 2017. 
GÓMEZ, Ángel I. Pérez. Educação na era digital: a escola educativa. Penso Editora, 2015.

GRILLO, Marlene; LIMA, V. M. Mapas conceituais e sua utilização na educação. 2003.

HERRERO, Jorge Luis Gomes Martin. Uma reflexão sobre uso das tics no cotidiano escolar a partir da experiência de estágio na licenciatura de história. Trabalho de Conclusão de Curso. Universidade Federal da Integração Latino-Americana, 2019.

LANGHI, Rodolfo; NARDI, Roberto. Ensino da astronomia no Brasil: educação formal, informal, não formal e divulgação científica. Revista Brasileira de Ensino de Física, p. 4402-4412, 2009.Machado, F. C., \& Lima, M. D. F. W. P. (2017). O Uso da Tecnologia Educacional: Um Fazer Pedagógico no Cotidiano Escolar. Scientia cum Industria, 5(2), 4450 .

MAFORT, Mariane Rentes; RAMOS, Laís Feliciano; FERNANDES-SANTOS, Caroline. Podcast como estratégia de inclusão no ensino superior. SocArXiv Paper, 2019.

MARTIN, João Alberto Prado et al. Uso da gamificação no ensino de marketing/Use of gamification in teaching marketing. Brazilian Applied Science Review, v. 2, n. 2, p. 734$745,2018$.

MEDEIROS, Magnólia Maria; QUEIROZ, Maria Jane. TICS NA EDUCAÇÃO: O USO DE SOFTWARE LIVRE NA PROMOÇÃO DA ACESSIBILIDADE. Revista Brasileira da Educação Profissional e Tecnológica, v. 1, n. 14, p. 6875, 2018.

MENEZES, Jones Baroni Ferreira; MOURA, Francisco Nunes Sousa; DE ARAÚJO SOUSA, Shirliane. Utilização das tecnologias digitais por docentes vinculados à cursos de licenciatura ofertados no município de Crateús-CE. Ciência \& Desenvolvimento-Revista Eletrônica da FAINOR, v. 12, n. 1, 2019.

MORAN, José Manuel; MASETTO, Marcos; BEHRENS, Marilda. Novas tecnologias e mediação pedagógica. 3 edição. 2001.

NUNES, João Batista Carvalho; OLIVEIRA, Luisa Xavier. Cultura digital: retrato do uso das tecnologias no Estado do Ceará. Fortaleza. EdUECE, 2014.

OLIVEIRA ALKIMIM, Wanderson. O lúdico no ensino e aprendizagem de botânica: fanerógamos no ensino superior. Heringeriana, v. 6, n. 1, p. 11-13, 2014.

OLIVEIRA MONTE, Ana Laís et al. Video wordfinder maker: ferramenta para criação de caça palavras sincronizadas com vídeos. Blucher Design Proceedings, v. 2, n. 9, p. 21782189, 2016.

OMS - ORGANIZAÇÃO MUNDIAL DA SAÚDE. Coronavirus disease (COVID-19) situation report-102. 2020. Disponível em: https://www.who.int/docs/defaultsource/coronaviruse/situation-reports/20200501-covid-19-sitrep.pdf?sfvrsn=742f4a18 2 . Acesso em 27 mai 2020.

QUINTANILHA, Luiz Fernando. Inovação pedagógica universitária mediada pelo Facebook e YouTube: uma experiência de ensino-aprendizagem direcionado à geração-Z. Educar em Revista, n. 65, p. 249-263, 2017. 
RAMOS, Lídia Maria Henrique; DE ARAÚJO, Robson Fágner Ramos. Uso de cartilha educacional sobre diabetes mellitus no processo de ensino e aprendizagem. Ensino, Saude e Ambiente Backup, v. 10, n. 3, 2018.

REIS, Deyse Almeida; VIEIRA JÚNIOR, Niltom Games como estratégia de ensino de ciências para abordar o saneamento básico. Research, Society and Development, v. 8, n. 12, p. e428121846-e428121846, 2019.

RODRIGUES, Alessandra Pereira; BEZ, Marta Rosecler; KONRATH, Mary Lúcia Pedroso. Objetos de aprendizagem: conceitos básicos. In: Tarouco et al. (Org.) Objetos de aprendizagem: teoria e prática. Porto Alegre: Evangraf, 2014.

RUSSELL, Philip et al. Creating, sharing and reusing learning objects to enhance information literacy. Journal of Information Literacy, v. 7, n. 2, p. 60-79, 2013.

SANTOS, Miriam Cristina Fava; CATARINO, Maria Elisabete. 25 anos da web e o marco civil da internet: o livre acesso à informação, a liberdade de expressão e a privacidade. Comunicação \& Informação, v. 19, n. 1, p. 05-19, 2016.

SILVA, Marcelo José; PEREIRA, Marcus Vinicius; ARROIO, Agnaldo. O papel do youtube no ensino de ciências para estudantes do ensino médio. Revista de Educação, Ciências e Matemática, v. 7, n. 2, 2017.

SILVA, Virginia Roters; LORENZETTI, Leonir. A UTILIZAÇÃO DOS MAPAS CONCEITUAIS NA PESQUISA EM EDUCAÇÃO EM CIÊNCIAS. REAMEC-Rede Amazônica de Educação em Ciências e Matemática, v. 6, n. 1, p. 43-64, 2018.

SOUZA FILHO, Moacir Pereira; DE SOUZA ALBAS, Agda Eunice; GIBIN, Gustavo Bizarria. Uso de recursos tecnológicos no ensino de ciências: produção de videoaulas didáticos-experimentais pelos futuros professores. Nuances: estudos sobre Educação, v. 28, n. 3, 2017.

TAROUCO, Liane Margarida Rockenbach. FABRE, Marie-Christine JM; TAMUSIUNAS, Fabricio; Reusabilidade de objetos educacionais. RENOTE-Revista Novas Tecnologias na Educação, v. 1, n. 1, 2003.

TEZANI, Thaís Cristina Rodrigues. A educação escolar no contexto das Tecnologias da Informação e da Comunicação: desafios e possibilidades para a prática pedagógica curricular. Revista Faac, v. 1, n. 1, p. 35-45, 2011.

THEISEN, Geovane Rafael; PAVÃO, Ana Cláudia Oliveira. E-book de ciências como ferramenta de apoio aos professores na promoção de aulas práticas. RENOTE-Revista Novas Tecnologias na Educação, v. 17, n. 1, p. 336-344, 2019.

Recebido em: 1 de setembro de 2020.

Aprovado em: 15 de outubro de 2020. 